\title{
MESP1 loss-of-function mutation contributes to double outlet right ventricle
}

\author{
MIN ZHANG $^{1 *}$, FU-XING LI $^{2 *}$, XING-YUAN LIU ${ }^{2}$, RI-TAI HUANG ${ }^{3}$, SONG XUE $^{3}$, XIAO-XIAO YANG ${ }^{4}$, \\ YAN-JIE $\mathrm{LI}^{4}, \mathrm{HUA} \mathrm{LIU}^{4}, \mathrm{HONG-YU} \mathrm{SHI}{ }^{4}, \mathrm{XIN} \mathrm{PAN}^{4}, \mathrm{XING-BIAO}$ QIU ${ }^{4}$ and YI-QING YANG ${ }^{4-6}$ \\ ${ }^{1}$ Department of Pediatrics, Shanghai Tenth People's Hospital, Tongji University School of Medicine, \\ Shanghai 200072; ${ }^{2}$ Department of Pediatrics, Tongji Hospital, Tongji University School of Medicine, \\ Shanghai 200065; ${ }^{3}$ Department of Cardiovascular Surgery, Renji Hospital, School of Medicine, Shanghai Jiao \\ Tong University, Shanghai 200127; ${ }^{4}$ Department of Cardiology; ${ }^{5}$ Cardiovascular Research Laboratory; \\ ${ }^{6}$ Central Laboratory, Shanghai Chest Hospital, Shanghai Jiao Tong University, Shanghai 200030, P.R. China
}

Received May 15, 2016; Accepted March 30, 2017

DOI: $10.3892 / \mathrm{mmr} .2017 .6875$

\begin{abstract}
Congenital heart disease (CHD) is the most common form of birth defect in humans, and remains a leading non-infectious cause of infant mortality worldwide. An increasing number of studies have demonstrated that genetic defects serve a pivotal role in the pathogenesis of CHD, and mutations in $>60$ genes have been causally associated with CHD. CHD is a heterogeneous disease and the genetic basis of CHD in the majority of patients remains poorly understood. In the present study, the coding exons and flanking introns of the mesoderm posterior 1 (MESPl) gene, which encodes a basic helix-loop-helix transcription factor required for normal cardiovascular development, were sequenced in 178 unrelated patients with CHD. The available relatives of the index patient carrying an identified mutation and 200 unrelated, ethnically-matched healthy individuals, who were used as controls, were genotyped for MESPI. The functional characteristics of the MESPI mutation were determined using a dual-luciferase reporter assay system. As a result, a novel de novo heterozygous MESPI mutation, p.Q118X, was identified in an index patient with double outlet right ventricle (DORV) and a ventricular septal defect. The nonsense mutation was
\end{abstract}

Correspondence to: Dr Xing-Yuan Liu, Department of Pediatrics, Tongji Hospital, Tongji University School of Medicine, 389 Xin Cun Road, Shanghai 200065, P.R. China

E-mail: xingyuanliu69@163.com

Dr Yi-Qing Yang, Cardiovascular Research Laboratory, Shanghai Chest Hospital, Shanghai Jiao Tong University, 241 West Huaihai Road, Shanghai 200030, P.R. China

E-mail: yang99yang66@hotmail.com

*Contributed equally

Key words: congenital heart disease, double outlet right ventricle, genetics, transcriptional factor, mesoderm posterior 1, reporter gene assay absent in the 400 reference chromosomes and the altered amino acid was completely conserved evolutionarily across species. Functional assays indicated that the mutant MESP1 protein had no transcriptional activity when compared with its wild-type counterpart. The present study firstly provided experimental evidence supporting the concept that a MESPI loss-of-function mutation may contribute to the development of DORV in humans, which presents a significant insight into the molecular pathogenesis of CHD. The results highlight the potential implications for the genetic counseling and personalized treatment of patients with CHD.

\section{Introduction}

Congenital heart disease (CHD), which commonly refers to a developmental abnormality in the structure of the heart or intrathoracic great blood vessel, is the most common type of birth defect in humans, accounting for one-third of all major congenital malformations worldwide (1). There are 1.35 million neonates born with CHD worldwide every year, with a global incidence of $\sim 1 \%$ in live births and as high as $10 \%$ in early miscarriages (1-3). At present, CHD remains the leading noninfectious cause of infant morbidity and mortality, and is estimated to account for $27 \%$ of all birth defect-associated cases of mortality (2). Despite the high prevalence and important clinical significance, the causes of CHD remain largely unclear.

The heart is the first functional organ to develop during vertebrate embryogenesis (4). The development of the cardiovascular system is a complex biological process that involves cell proliferation, differentiation, polarization and migration, and is extremely sensitive to environmental and genetic risk factors $(4,5)$. Errors during the process of cardiovascular morphogenesis may result in a broad spectrum of congenital cardiovascular anomalies, including ventricular septal defect (VSD), atrial septal defect, tetralogy of Fallot, double outlet right ventricle (DORV), transposition of the great arteries and endocardial cushion defect (6-8). Although there are nongenetic risk factors associated with $\mathrm{CHD}$, including parental characteristics and conditions, maternal drug use in the first 
trimester of pregnancy, and long-term exposure to toxicants and ionizing radiation (9), an increasing body of evidence in the field of human genetics has demonstrated that genetic defects serve a key role in the pathogenesis of CHD, and to date, a large number of mutations in $>60$ genes have been causally linked to CHD (6-8,10-35). Among these established CHD-associated genes, the majority encode cardiac transcription factors $(6-8,36)$. However, $\mathrm{CHD}$ is a heterogeneous disorder, and the genetic components underlying CHD in the majority of patients remain unclear.

Mesoderm posterior 1 (MESP1), also known as class C basic helix-loop-helix (bHLH) protein 5 , is expressed in the posterior part of the embryonic mesoderm and is an important transcription factor expressed in cardiac progenitors during embryogenesis. It is also the earliest marker identified once a cell has been committed towards cardiac development $(37,38)$. In mice, inactivation of the MESPI gene leads to mortality due to abnormalities in heart tube formation and heart looping, resulting in various degrees of cardiac bifida $(39,40)$. By contrast, overexpression of MESPI in mouse embryonic stem cells results in abnormal expression of specific gene sets and, subsequently, accelerated cardiovascular specification and premature appearance of beating cells (41). Among these upregulated genes are crucial cardiovascular transcription factors including NKX2 homeobox 5 (NKX2-5), GATA binding protein 4 (GATA4), T-box 20 (TBX20), heart and neural crest derivatives expressed 2 (HAND2) and myocardin (MYOCD) (41), of which certain genes (NKX2-5, GATA4, $T B X 20$ and $H A N D 2)$ are involved in the pathogenesis of CHD in humans $(13,19,24,27,31-36,42-44)$. In humans, mutations in MESP1 have been demonstrated to contribute to various types of CHD, including VSD, atrial septal defect, tetralogy of Fallot, coarctation of the aorta and aortic atresia $(41,45)$. However, the prevalence and variety of the MESP1 mutations in Chinese patients with CHD have yet to be investigated.

\section{Materials and methods}

Study patients and control individuals. In the present study, a cohort of 178 Chinese Han unrelated patients diagnosed with non-syndromic CHD were recruited from the following hospitals: Shanghai Tenth People's Hospital, Tongji Hospital, Renji Hospital and Shanghai Chest Hospital (Shanghai, China), between February 2013 and March 2015. The available family members of the index patient carrying an identified MESPI mutation were also included. A total of 95 males and 83 females, of which 9 had a positive family history of CHD were included. A total of 200 ethnically-matched healthy individuals, who had no CHD diagnosis, family history of CHD or any other heart disease, were recruited as controls from the following hospitals: Shanghai Tenth People's Hospital, Tongji Hospital, Renji Hospital and Shanghai Chest Hospital (Shanghai, China), between February 2013 and March 2015. A total of 107 males and 93 females, with no family history of CHD were recruited. All study participants underwent detailed clinical evaluation, including medical histories, physical examination (including assessment for shortness of breath, cyanosis, heart murmur, under-development of limbs or poor growth), 12-lead electrocardiogram and two-dimensional transthoracic echocardiography with color flow Doppler. Transesophageal echocardiography or cardiac catheterization procedure was performed only when clinically indicated. Diagnosis of CHD was confirmed by imaging and/or direct view during cardiac surgery. Subjects with a recognizable syndromic CHD at the time of enrollment, including Down syndrome, Holt-Oram syndrome, Di George syndrome and Turner syndrome, were excluded from the study. The present study was conducted in accordance with the ethical principles outlined in the Declaration of Helsinki. The study protocol was approved by the Institutional Ethical Committee of the Tongji Hospital, Tongji University School of Medicine, China [project no. LL (H)-09-07]. Informed written consent was obtained from the guardians of the patients with CHD and the control individuals prior to the collection of blood samples.

DNA isolation and mutation analysis. Peripheral venous blood samples were drawn from all study subjects. Genomic DNA was isolated from whole blood cells using the Wizard Genomic DNA Purification kit (Promega Corporation, Madison, WI, USA), according to the manufacturer's recommendation. Based on the referential genomic DNA sequence of the MESPI gene (GenBank accession no.: NC_000015.10), which was derived from the National Center for Biotechnology Information (NCBI; http://www.ncbi.nlm.nih.gov/), the primer pairs used to amplify the coding exons and splicing junctions of MESPl by polymerase chain reaction (PCR) were designed as presented in Table I. DNA samples were amplified using HotStar Taq DNA Polymerase (Qiagen GmbH, Hilden, Germany) on a Verti Thermal Cycler (Applied Biosystems; Thermo Fisher Scientific, Inc., Waltham, MA, USA) with standard thermocycling conditions. The total volume of the PCR mixture was $25 \mu \mathrm{l}$, comprising $11.25 \mu \mathrm{l}$ deionized water, $2.5 \mu 110 \mathrm{X}$ buffer, $5 \mu 15 \mathrm{X}$ Q solution, $2 \mu \mathrm{ldNTPs}(2.5 \mathrm{mM}$ each), $1 \mu \mathrm{l}$ of each primer $(20 \mu \mathrm{M}), 0.25 \mu \mathrm{l}(5 \mathrm{U} / \mu \mathrm{l})$ HotStar Taq DNA Polymerase (Qiagen, Hilden, Germany) and $2 \mu \mathrm{l}$ of genomic DNA (200 ng/ $\mu \mathrm{l})$. Thermocycling conditions were as follows: Initial denaturation at $95^{\circ} \mathrm{C}$ for $15 \mathrm{~min}$, followed by 35 cycles of denaturation at $94^{\circ} \mathrm{C}$ for $30 \mathrm{sec}$, annealing at $62^{\circ} \mathrm{C}$ for $30 \mathrm{sec}$ and extension at $72^{\circ} \mathrm{C}$ for $1 \mathrm{~min}$, with a final extension at $72^{\circ} \mathrm{C}$ for $10 \mathrm{~min}$. PCR products were purified with a QIAquick PCR Purification kit (Qiagen $\mathrm{GmbH}$ ), according to the manufacturer's protocol, and subjected to PCR-sequencing with a BigDye ${ }^{\circledR}$ Terminator v3.1 Cycle Sequencing kit (Applied Biosystems; Thermo Fisher Scientific, Inc.) under an ABI PRISM 3130 XL DNA Analyzer (Applied Biosystems; Thermo Fisher Scientific, Inc.). The total volume of the PCR sequencing mixture was $20 \mu 1$, including $8 \mu 1$ deionized water, $8 \mu \mathrm{l}$ Premix, $1 \mu \mathrm{l}$ forward or reverse primer $(2 \mu \mathrm{M})$ and $3 \mu \mathrm{l}$ of the purified DNA products $(20 \mathrm{ng} / \mu \mathrm{l})$. The sequencing PCR program was set as follows: A total of 35 cycles of denaturation at $95^{\circ} \mathrm{C}$ for $20 \mathrm{sec}$, annealing at $50^{\circ} \mathrm{C}$ for $15 \mathrm{sec}$ and extension at $60^{\circ} \mathrm{C}$ for $1 \mathrm{~min}$. The obtained sequences were compared with the genomic reference sequence (GenBank accession no.: NC_000015.10) using the Basic Local Alignment Search Tool (BLAST; https://blast.ncbi. nlm.nih.gov/Blast.cgi?PAGE_TYPE=BlastSearch\&PROG_ $\mathrm{DEF}=$ blastn\&BLAST_PROG_DEF=blastn\&BLAST_SPEC $=$ GlobalAln\&LINK_LOC=BlastHomeLink; National Center for Biotechnology Information, Bethesda, MD, USA). For 
Table I. Primers for amplification of the coding exons and flanking introns of the Mesoderm Posterior 1 gene.

\begin{tabular}{lllc}
\hline Exon & \multicolumn{1}{c}{ Forward primer (5'-3') } & \multicolumn{1}{c}{ Reverse primer (5'-3') } & Amplicon (base pairs) \\
\hline $1-\mathrm{a}$ & ACCTCGGGCTCGGCATAAAG & GCAGTTTCTCCCGCTCACTG & 340 \\
$1-\mathrm{b}$ & TCGTCTCGTCCCCAGACTCA & GGTGCCTGGTCCTCACCTT & 699 \\
2 & GAAGGGCAGGCGATGGAGC & GAGGCCAAAAAGCCTCGGTG & 450 \\
\hline
\end{tabular}

an identified sequence variation, a second independent PCR analysis was performed, as aforementioned, to confirm it. The position of an exonic variation is described according to the guidelines of the human genome variation society using the NCBI reference sequence of the MESPI mRNA (NM_018670.3). For a newly discovered genetic variation, the public databases for human sequence variations, including single nucleotide polymorphism (SNP; http://www.ncbi. nlm.nih.gov/SNP), the 1000 Genomes Project (1000 GP; http://www.1000genomes.org/) and human gene mutation (HGM; http://www.hgmd.org) databases, were consulted to confirm its novelty.

Multiple alignments of the MESP1 protein across species. The human MESP1 protein was autonomously aligned with those of a chimpanzee, monkey, dog, mouse and rat, using Multiple Sequence Comparison by Log-Expectation (MUSCLE; http://www.ebi.ac.uk/Tools/msa/muscle/; European Bioinformatics Institute, Hinxton, UK).

Expression plasmids and site-directed mutagenesis. Human heart cDNAs were prepared as described previously (46). The full-length wild-type cDNAs of the human MESPl gene were amplified by PCR using the pfuUltra high-fidelity DNA polymerase (Stratagene; Agilent Technologies, Inc., Santa Clara, CA, USA) and the following primers: Forward, 5'-ATG GCTAGCTGGAAGGGGCCACTTCACAC-3' and reverse, 5'-CATTCTAGAGACGGCGTCAGTTGTCC-3'. The total volume of the PCR mixture was $50 \mu 1$, including $36 \mu 1$ deionized water, $5 \mu \mathrm{l} 10 \mathrm{X}$ buffer, $4 \mu \mathrm{l}$ dNTPs (2.5 mM each), $1 \mu \mathrm{l}$ of each primer $(20 \mu \mathrm{M}), 1 \mu \mathrm{l}(2.5 \mathrm{U} / \mu \mathrm{l})$ pfuUltra high-fidelity DNA polymerase and $2 \mu \mathrm{l}$ cDNA (100 ng/ $\mu \mathrm{l})$. Thermocycling conditions were as follows: Initial denaturation at $95^{\circ} \mathrm{C}$ for $2 \mathrm{~min}$, followed by 35 cycles of denaturation at $95^{\circ} \mathrm{C}$ for $1 \mathrm{~min}$, annealing at $62^{\circ} \mathrm{C}$ for $30 \mathrm{sec}$ and extension at $72^{\circ} \mathrm{C}$ for $1 \mathrm{~min}$, with a final elongation at $72^{\circ} \mathrm{C}$ for $10 \mathrm{~min}$. The PCR fragment was doubly digested by endonucleases $\mathrm{NheI}$ and $\mathrm{XbaI}$ (Takara Biotechnology Co., Ltd., Dalian, China). The digested product (40 $\mu \mathrm{l} /$ lane), with a length of 912 base pairs, was fractionated by $1.5 \%$ agarose gel electrophoresis, purified with the QIAquick Gel Extraction kit (Qiagen $\mathrm{GmbH}$ ), according to the manufacturer's protocol, and then inserted into pcDNA3.1 (Promega Corporation) to construct the eukaryotic expression vector, pcDNA3.1-MESP1. Similarly, the full-length wild-type cDNAs of the human E47 gene [also termed transcription factor 3 (TCF3) isoform 2] were amplified by PCR using the following primers: Forward, 5'-GGTGCTAGCGGTTTCCAG GCCTGAGGTGC-3' and reverse, 5'-CCATCTAGACAA AGTGTATGTTTTGTTGC-3', and doubly digested by NheI and XbaI (Takara Biotechnology Co., Ltd.). Thermocycling conditions were as follows: Initial denaturation at $95^{\circ} \mathrm{C}$ for 2 min, followed by 35 cycles of denaturation at $95^{\circ} \mathrm{C}$ for $1 \mathrm{~min}$, annealing at $62^{\circ} \mathrm{C}$ for $30 \mathrm{sec}$ and extension at $72^{\circ} \mathrm{C}$ for $2 \mathrm{~min}$, with a final elongation at $72^{\circ} \mathrm{C}$ for $10 \mathrm{~min}$. The digested product, with a length of 2,044 base pairs, was subcloned into pcDNA3.1 (Promega Corporation) to construct the recombinant plasmid pcDNA3.1-E47. The Ebox-luc [pGL4.23-Dickkopf WNT signaling pathway inhibitor 1 (DKK1)-11] plasmid, which contains a triplicate repeat of the E-box region acCATATGgt located $\sim 11.6 \mathrm{~kb}$ upstream of $D K K 1$ and expresses Firefly luciferase (47), was constructed as described previously (41). The identified mutation was introduced into wild-type MESPI by site-directed mutagenesis using a QuickChange II XL Site-Directed Mutagenesis kit (Stratagene; Agilent Technologies, Inc.) with the following mutagenic primers: Forward, 5'-GTGGCGCCCGCGGGCTAGAGCCTGACCAAGA-3' and reverse, 5'-TCTTGGTCAGGCTCTAGCCCGCGGGCG CCAC-3'. The mutant was selected by DpnI (Takara Biotechnology Co., Ltd.) digestion and then sequenced for verification. Sequencing was performed as aforementioned using the following primers at either side of the multiple cloning sites of the pcDNA3.1 plasmid: Forward, 5'-TAATACGACTCACTA TAGGG-3' and reverse, 5'-TAGAAGGCACAGTCGAGG-3'.

Dual-luciferase reporter assays. Human embryonic kidney (HEK) 293 cells were purchased from the Shanghai Institute of Biochemistry and Cell Biology, Shanghai Institutes for Biological Sciences, Chinese Academy of Sciences (Shanghai, China) were cultured in Dulbecco's modified Eagle's medium supplemented with $10 \%$ fetal calf serum (Invitrogen; Thermo Fisher Scientific, Inc.) at $37^{\circ} \mathrm{C}$, and plated at a density of $1 \times 10^{5}$ cells/well on 24-well plates $24 \mathrm{~h}$ prior to transfection. Cells were cotransfected with either $100 \mathrm{ng}$ empty pcDNA3.1 vector (-), 100 ng wild-type MESP1-pcDNA3.1 vector (MESP1), 100 ng Q118X-mutant MESP1-pcDNA3.1 vector (Q118X) or $50 \mathrm{ng}$ wild-type MESP1-pcDNA3.1 vector plus $50 \mathrm{ng}$ Q118X-mutant MESP1-pcDNA3.1 vector (MESP1 + Q118X), together with $250 \mathrm{ng}$ pcDNA3.1-E47, $100 \mathrm{ng}$ Ebox-luc vector and 0.4 ng pGL4.75 (a Renilla luciferase reporter vector, which was used as an internal control to normalize transfection efficiency) using the PolyFect Transfection Reagent (Qiagen $\mathrm{GmbH}$ ), according to the manufacturer's protocol. Transfected cells were incubated for $48 \mathrm{~h}$ at $37^{\circ} \mathrm{C}$ with $5 \% \mathrm{CO}_{2}$, then lysed with Passive Lysis Buffer (Promega Corporation) and assayed with the Dual-Glo luciferase assay kit (Promega Corporation) on a GloMax ${ }^{\circledR} 96$ Luminometer (Promega Corporation) according to the manufacturer's protocol. Firefly luciferase and Renilla luciferase activities were analyzed using the GloMax ${ }^{\circledR} 96$ Microplate Luminometer software version 1.9.3 (Promega Corporation), and the activity of the Ebox promoter 
was presented as fold activation of Firefly luciferase relative to Renilla luciferase. A minimum of three independent cotransfection experiments were performed in triplicate to calculate the average values and standard deviations.

Statistical analysis. Statistical analyses were performed using the SPSS software version 17.0 (SPSS, Inc., Chicago, IL, USA). Continuous variables are expressed as the mean \pm standard deviation, and categorical variables are expressed as numbers and percentages. The statistical significance of the differences between groups was assessed using a one-way analysis of variance followed by a post hoc Bonferroni test for multiple comparisons. $\mathrm{P}<0.05$ was considered to indicate a statistically significant difference.

\section{Results}

Clinical characteristics of the study subjects. A cohort of 178 unrelated patients with was clinically evaluated in comparison with a total of 200 unrelated non-CHD control individuals. All of the patients had confirmed CHD diagnoses; while the control individuals had no congenital anomalies in cardiovascular structures. There was no statistical difference in age, gender or ethnicity between the patient and control groups. The baseline clinical features of the 178 patients with CHD are summarized in Table II.

Identification of a novel MESP1 mutation in CHD. Direct PCR-sequencing of the MESPI gene in 178 unrelated patients with CHD identified a heterozygous nonsense mutation in one patient, with a mutational prevalence of $\sim 0.56 \%$. More specifically, a substitution of thymine for cytosine in the first nucleotide of codon 118 (c.352C $>\mathrm{T}$ ), predicting the transition of the codon coding for glutamine into a stop codon at amino acid position 118 (p.Q118X), was detected in a 3-month-old female with DORV and VSD. The sequence chromatograms depicting the heterozygous MESP1 mutation in addition to its control sequence are presented in Fig. 1. A schematic diagram displaying the location of the identified mutation and the bHLH structural domain of the MESP1 protein is presented in Fig. 2 (48). The nonsense mutation was not identified in the 400 reference chromosomes or in the SNP, 1000 GP and HGM databases (consulted July 5th, 2016). The mutation carrier had no family history of CHD and her parents had no CHD. Genetic screening of the mutation carrier's parents identified that the mutation was absent in her parents, indicating that it is a de novo mutation.

Alignment of multiple MESP1 sequences across species. As presented in Fig. 3, a cross-species alignment of the MESP1 protein sequences indicated that the altered amino acid glutamine at position 118 was completely conserved evolutionarily.

Transcriptional activation of Q118X-mutant MESP1. It has been demonstrated that MESP1 binds to the promoter regions containing putative bHLH-binding sites (Eboxes) of several transcription factors (41). However, MESP1 does not bind to Eboxes alone, it forms heterodimers with E47 or E12 (E47 and E12 are two isoforms of TCF3, a member of the ubiquitous
Table II. Clinical characteristics of the patients with congenital heart disease.

\begin{tabular}{|c|c|c|}
\hline Variable & Number & $\begin{array}{c}\text { Percentage } \\
(\%) \text { or } \\
\text { range }\end{array}$ \\
\hline \multicolumn{3}{|l|}{ Gender } \\
\hline Male & 95 & 53 \\
\hline Female & 83 & 47 \\
\hline Age (years; mean) & 4 & $0-21$ \\
\hline Positive family history of CHD & 9 & 5 \\
\hline \multicolumn{3}{|l|}{ Distribution of various CHDs } \\
\hline Isolated CHD & 92 & 52 \\
\hline VSD & 30 & 17 \\
\hline ASD & 14 & 8 \\
\hline DORV & 10 & 6 \\
\hline PS & 8 & 4 \\
\hline TGA & 6 & 3 \\
\hline TA & 6 & 3 \\
\hline HLV & 5 & 3 \\
\hline PA & 4 & 2 \\
\hline TAPVC & 3 & 2 \\
\hline AS & 3 & 2 \\
\hline IAA & 2 & 1 \\
\hline AVSD & 1 & 1 \\
\hline Complex CHD & 86 & 48 \\
\hline TOF & 28 & 16 \\
\hline VSD + ASD & 17 & 10 \\
\hline DORV + VSD & 15 & 8 \\
\hline $\mathrm{VSD}+\mathrm{PDA}$ & 12 & 7 \\
\hline TGA + VSD & 8 & 4 \\
\hline TA + VSD & 6 & 3 \\
\hline \multicolumn{3}{|l|}{ Incidence of arrhythmias } \\
\hline Atrioventricular block & 6 & 3 \\
\hline Atrial fibrillation & 4 & 2 \\
\hline \multicolumn{3}{|l|}{ Treatment } \\
\hline Surgical repair & 109 & 61 \\
\hline Percutaneous closure & 41 & 23 \\
\hline Follow-up & 28 & 16 \\
\hline
\end{tabular}

Total number of patients $=178$. CHD, congenital heart disease; VSD, ventricular septal defect; ASD, atrial septal defect; DORV, double outlet right ventricle; PS, pulmonary stenosis; TGA, transposition of the great arteries; TA, truncus arteriosus; HLV, hypoplastic left ventricle; PA, pulmonary atresia; TAPVC, total abnormal pulmonary venous connection; AS, aortic stenosis; IAA, interrupted aortic arch; AVSD, atrioventricular septal defect; TOF, tetralogy of Fallot; PDA, patent ductus arteriosus.

E-protein family of bHLH transcription factors) in order to activate transcription. In addition, it has been demonstrated that the MESP1/E47 heterodimer activates transcription significantly more than either one alone (41). Thus, in order to assess the effect of a mutation on MESP1 transcriptional activity, E47 was used in the present study. As presented in 
Table III. Mesoderm posterior 1 mutations associated with congenital heart diseases in humans.

\begin{tabular}{|c|c|c|c|c|c|c|}
\hline Author, year & $\begin{array}{l}\text { Nucleotide } \\
\text { change }\end{array}$ & $\begin{array}{l}\text { Amino acid } \\
\text { change }\end{array}$ & $\begin{array}{l}\text { Effect on } \\
\text { protein function }\end{array}$ & $\begin{array}{c}\text { Cardiac } \\
\text { structural defects }\end{array}$ & $\begin{array}{l}\text { Familial/ } \\
\text { sporadic }\end{array}$ & Refs. \\
\hline Werner et al, 2016 & c.79_87 dup9 & p.P27_D29 dup & No significant effect & VSD & Familial & (41) \\
\hline Werner et al, 2016 & c. $209 \mathrm{G}>\mathrm{A}$ & p.G70D & No significant effect & VSD & $\mathrm{n} / \mathrm{a}$ & (41) \\
\hline Werner et al, 2016 & c. $310 \mathrm{G}>\mathrm{A}$ & p.E104K & Loss of function & TOF & Familial & (41) \\
\hline Werner et al, 2016 & c. $359 \mathrm{~T}>\mathrm{C}$ & p.L120P & Loss of function & TOF & Sporadic & (41) \\
\hline Werner et al, 2016 & c.436_437 delAG & p.L147PfsX9 & Loss of function & VSD & $\mathrm{n} / \mathrm{a}$ & (41) \\
\hline Werner et al, 2016 & c. $503 \mathrm{~A}>\mathrm{G}$ & p.D168G & No significant effect & VSD & $\mathrm{n} / \mathrm{a}$ & (41) \\
\hline Werner et al, 2016 & c. $804 \mathrm{G}>\mathrm{C}$ & p.K268N & No significant effect & VSD, CoA, AA & Familial & $(41)$ \\
\hline Lahm et al, 2013 & c. $33 \mathrm{G}>\mathrm{C}$ & p.E11D & Gain of function & TOF & $\mathrm{n} / \mathrm{a}$ & $(45)$ \\
\hline Lahm et al, 2013 & c. $528 \mathrm{~A}>\mathrm{T}$ & p.T176S & No significant effect & ASD & $\mathrm{n} / \mathrm{a}$ & $(45)$ \\
\hline Zhang et al, 2017 & c. $352 \mathrm{C}>\mathrm{T}$ & p.Q118X & Loss of function & DORV, VSD & Sporadic & Present study \\
\hline
\end{tabular}

VSD, ventricular septal defect; TOF, tetralogy of Fallot; CoA, coarctation of the aorta; AA, aortic atresia; ASD, atrial septal defect; DORV, double outlet of right ventricle; NA, not available.

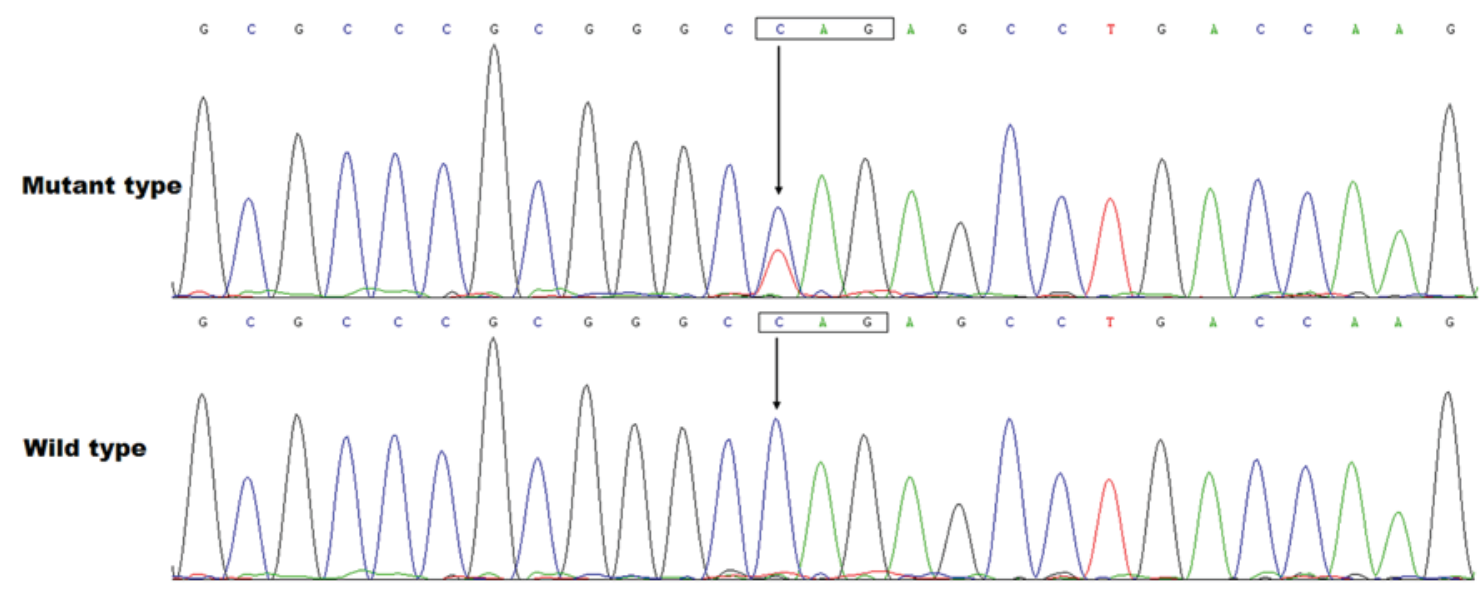

Figure 1. Representative electropherograms displaying the MESP1 mutation sequence and its wild-type control. The arrow points to the heterozygous nucleotides of $\mathrm{C} / \mathrm{T}$ in the patient (mutant) or the homozygous nucleotides of $\mathrm{C} / \mathrm{C}$ in the control individual (wild type). The rectangle highlights the nucleotides that comprise a codon of MESP1. MESP 1, mesoderm posterior 1.

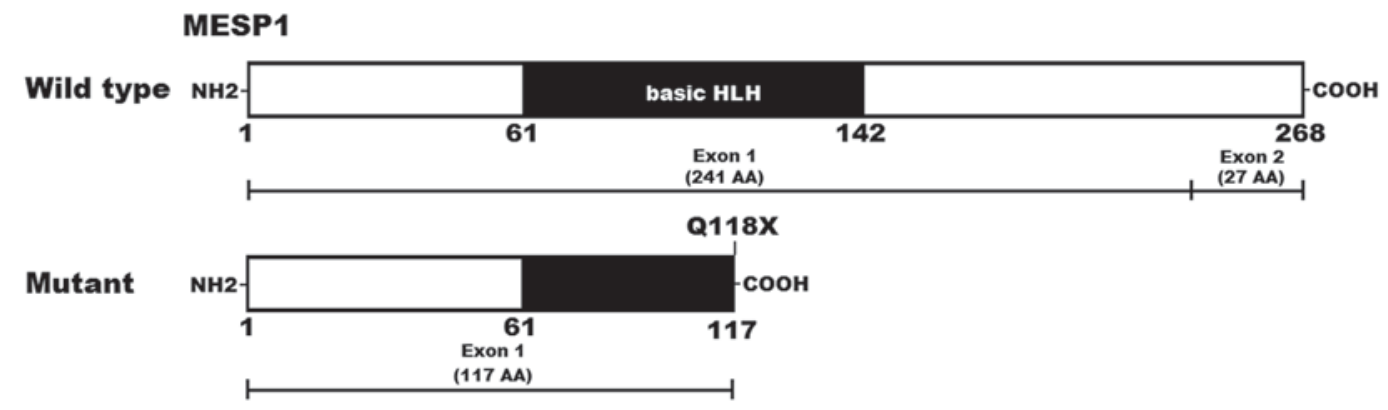

Figure 2. Schematic diagram depicting the structural domain of MESP1 with the mutation responsible for congenital heart disease (Q118X). The mutation associated with congenital heart disease is denoted above the structural domain. MESP 1, mesoderm posterior 1; NH2, amino-terminus; HLH, helix-loop-helix; AA, amino acid; $\mathrm{COOH}$, carboxyl-terminus.

Fig. 4, in the presence of E47, the wild-type MESP1 and the Q118X-mutant MESP1 (Q118X) activated the Ebox-containing promoter by $\sim 14$-fold and $\sim 1$-fold, respectively. When wild-type MESP1 was co-expressed with the same amount of
Q118X-mutant MESP1, the induced transcriptional activation was $~ 7$-fold. These results indicate that mutant MESP1 does not have transcriptional activity or a dominant-negative effect on its wild-type counterpart. 


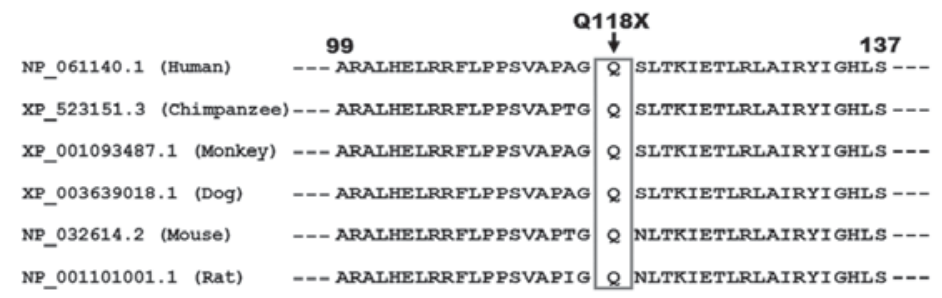

Figure 3. Multiple alignments of the MESP1 protein sequences across different species. The altered glutamine at amino acid position 118 (p.Q118) of MESP1 is completely conserved evolutionarily across the various species. MESP 1, mesoderm posterior 1 .

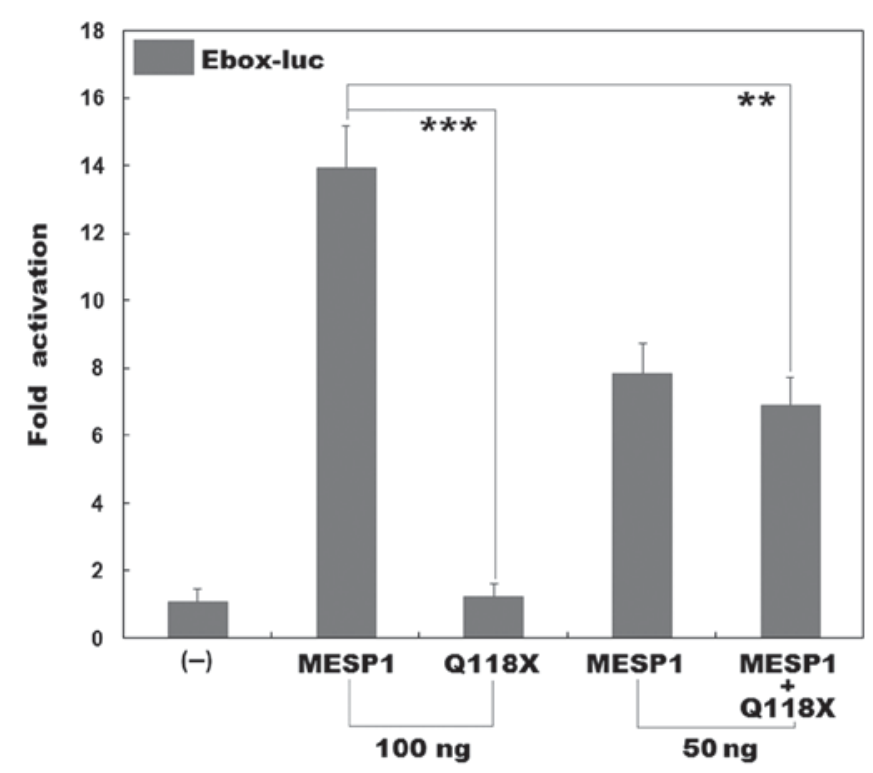

Figure 4. Transcriptional activation of the Ebox-containing promoter by MESP1/E47. Activation of the Ebox-containing reporter in cultured HEK 293 cells by wild-type or mutant (Q118X) MESP1, alone or in combination, exhibited significantly reduced transcriptional activity by the mutant protein in the presence of E47. Three independent experiments were performed in triplicate. Data are presented as the mean \pm standard deviation. ${ }^{* *} \mathrm{P}<0.01(\mathrm{t}=8.2170, \mathrm{P}=0.0012)$ and ${ }^{* * * *} \mathrm{P}=0.0001(\mathrm{t}=16.9937)$ vs wild-type MESP1. MESP 1, mesoderm posterior 1; HEK, human embryonic kidney; MESP1 group, wild-type MESP1-pcDNA3.1 vector; Q118X group, Q118X-mutant MESP1-pcDNA3.1 vector; MESP1 + Q118X group, wild-type MESP1-pcDNA3.1 vector plus Q118X-mutant MESP1-pcDNA3.1.

\section{Discussion}

In the present study, a novel heterozygous mutation in MESPI, p.Q118X, was discovered in a patient with DORV and VSD. The mutant allele was absent in the unaffected relatives examined and in 400 control chromosomes. A cross-species alignment of the MESP1 protein sequences indicated that the altered amino acid was completely conserved evolutionarily. Biological assays demonstrated that mutant MESP1 had no transcriptional activity. Therefore, genetically compromised MESP1 may predispose an individual to DORV and VSD.

The MESPI gene maps on to human chromosome 15q26.1, which contains 2 exons and codes for a bHLH transcription factor with 268 amino acids that is crucial for normal cardiovascular development (38). The bHLH domain is required for DNA sequence recognition and binding to the consensus motif of CATATG (Ebox) within the promoters of target genes; it is also responsible for protein-protein interactions $(38,41,48)$.
However, MESP1 do not bind to Eboxes alone and instead form heterodimers with E47 or E12 in order to activate transcription (41). E47 and E12 are two isoforms of TCF3, a member of the ubiquitous E-protein family of bHLH transcription factors (41). It has been demonstrated that the MESP1/E47 heterodimer activates transcription significantly more using a previously identified MESP1 binding Ebox motif in the DKK1 enhancer when compared with either one alone (41). In the present study, the p.Q118X mutation detected in a patient with CHD was located in the bHLH domain and is predicted to produce a truncated protein with only a partial bHLH domain left. Thus it may prevent the transcriptional activation of MESP1, which was verified by functional analysis. Overall, these results together with previous reports $(41,45)$ strongly suggest that a MESPI loss-of-function mutation is an alternative molecular mechanism underpinning CHD.

An association between genetically defective MESPI and enhanced susceptibility to CHD has been reported in mouse models. Genetic lineage tracing in mice indicated that MESPI was the earliest marker of cardiovascular progenitors, tracing almost all of the cardiac cells including derivatives of the primary and second heart fields, and serves a pivotal role in cardiovascular morphogenesis, particularly during the early specification and migration of cardiac precursors $(37,38)$. Homozygous MESPI-null mice suffered embryonic mortality due to defects in heart tube formation and looping, resulting in various degrees of cardia bifida from full to partial bifurcations, which was most likely induced by the delay in mesodermal migration and failure of ventral mesoderm fusion (37-40). In addition, a number of studies have indicated that MESP1 resides at the top of a large transcriptional hierarchy that regulates the expression of 423 genes, representing $1.3 \%$ of the murine transcriptome $(38,41)$. Among the genes upregulated by MESP1, there are a number of genes encoding cardiovascular core transcription factors, including $N K X 2-5$, GATA4, TBX2O and HAND2 (41). In addition, targeted inactivation of NKX2-5, GATA4, TBX20 or HAND2 in mice has been demonstrated to cause embryonic lethality with various cardiovascular developmental anomalies (49-56). These experimental results suggest that the MESPI loss-of-function mutation may contribute to CHD in humans.

In humans, MESPI variations have been causally linked to a number of CHDs. By high-resolution melting curve analysis and sequencing, Werner et al (41) scanned the coding exons and flanking introns of MESP1 in 647 unrelated patients with congenital conotruncal and associated heart defects, and identified 6 rare, nonsynonymous variants that were not seen in ethnically matched controls, and 1 likely race-specific 
nonsynonymous variant. Functional analyses identified that three of these variants reduced the activation of transcription by MESP1. Lahm et al (45) sequenced the coding regions of MESP1 in 215 unrelated patients with congenital heart disease, and identified two missense mutations in two patients that were absent in the controls. Biological assays demonstrated that one mutant had an enhanced transcriptional activity, however, the other had no functional alteration. These well-established CHD-associated MESPI mutations are summarized in Table III. These results coupled with those of the present study suggest that pathologic mutations in MESP1 may predispose individuals to CHD.

In conclusion, the results of the present study indicate that there is an association between the MESP1 loss-of-function mutation and an increased susceptibility to DORV in humans. This widens the known mutational spectrum of MESPI associated with CHD and highlights the potential broader role of MESP1 in cardiovascular development and CHD. Thus, the present study provides evidence for the potential implications of genetic counseling and he development of personalized therapeutic strategies for the treatment of patients with CHD.

\section{Acknowledgements}

The present study was supported by the Key Program for Basic Research of Shanghai, China (grant no. 14JC1405500), the National Natural Science Fund of China (grant nos. 81470372 and 81641014), the Natural Science Fund of Shanghai, China (grant no. 16ZR1432500) and the Key Project for Basic Research of Shanghai Chest Hospital, China (grant no. 2014YZDH10102).

\section{References}

1. Postma AV, Bezzina CR and Christoffels VM: Genetics of congenital heart disease: The contribution of the noncoding regulatory genome. J Hum Genet 61: 13-19, 2016.

2. Writing Group Members, Mozaffarian D, Benjamin EJ, Go AS, Arnett DK, Blaha MJ, Cushman M, Das SR, de Ferranti S, Després JP, et al: Heart Disease and Stroke Statistics-2016 Update: A Report From the American Heart Association. Circulation 133: e38-e360, 2016.

3. van der Linde D, Konings EE, Slager MA, Witsenburg M Helbing WA, Takkenberg JJ and Roos-Hesselink JW: Birth prevalence of congenital heart disease worldwide: A systematic review and meta-analysis. J Am Coll Cardiol 58: 2241-2247, 2011.

4. Zhu H: Forkhead box transcription factors in embryonic heart development and congenital heart disease. Life Sci 144: 194-201, 2016.

5. Bruneau BG: The developmental genetics of congenital heart disease. Nature 451: 943-948, 2008.

6. Fahed AC, Gelb BD, Seidman JG and Seidman CE: Genetics of congenital heart disease: The glass half empty. Circ Res 112: 707-720, 2013

7. Andersen TA, Troelsen Kde L and Larsen LA: Of mice and men: Molecular genetics of congenital heart disease. Cell Mol Life Sci 71: 1327-1352, 2014

8. Lalani SR and Belmont JW: Genetic basis of congenital cardiovascular malformations. Eur J Med Genet 57: 402-413, 2014.

9. Patel SS and Burns TL: Nongenetic risk factors and congenital heart defects. Pediatr Cardiol 34: 1535-1555, 2013.

10. Zaidi S, Choi M, Wakimoto H, Ma L, Jiang J, Overton JD, Romano-Adesman A, Bjornson RD, Breitbart RE, Brown KK, et al: De novo mutations in histone-modifying genes in congenital heart disease. Nature 498: 220-223, 2013.

11. Al Turki S, Manickaraj AK, Mercer CL, Gerety SS, Hitz MP, Lindsay S, D'Alessandro LC, Swaminathan GJ, Bentham J, Arndt AK, et al: Rare variants in NR2F2 cause congenital heart defects in humans. Am J Hum Genet 94: 574-585, 2014.
12. Werner P, Paluru P, Simpson AM, Latney B, Iyer R, Brodeur GM and Goldmuntz E: Mutations in NTRK3 suggest a novel signaling pathway in human congenital heart disease. Hum Mutat 35: 1459-1468, 2014.

13. Xiang R, Fan LL, Huang H, Cao BB, Li XP, Peng DQ and Xia K: A novel mutation of GATA4 (K319E) is responsible for familial atrial septal defect and pulmonary valve stenosis. Gene 534: 320-323, 2014

14. Shi LM, Tao JW, Qiu XB, Wang J, Yuan F, Xu L, Liu H, Li RG, $\mathrm{Xu}$ YJ, Wang Q, et al: GATA5 loss-of-function mutations associated with congenital bicuspid aortic valve. Int J Mol Med 33: 1219-1226, 2014.

15. Huang RT, Xue S, Xu YJ, Zhou M and Yang YQ: Somatic GATA5 mutations in sporadic tetralogy of Fallot. Int J Mol Med 33: 1227-1235, 2014.

16. Wang X, Ji W, Wang J, Zhao P, Guo Y, Xu R, Chen S and Sun K: Identification of two novel GATA6 mutations in patients with nonsyndromic conotruncal heart defects. Mol Med Rep 10: 743-748, 2014.

17. Zhao L, Ni SH, Liu XY, Wei D, Yuan F, Xu L, Xin-Li, Li RG, $\mathrm{Qu} \mathrm{XK}, \mathrm{Xu} \mathrm{YJ}$, et al: Prevalence and spectrum of Nkx2.6 mutations in patients with congenital heart disease. Eur J Med Genet 57: 579-586, 2014.

18. Cowan J, Tariq M and Ware SM: Genetic and functional analyses of ZIC3 variants in congenital heart disease. Hum Mutat 35: 66-75, 2014.

19. Qu XK, Qiu XB, Yuan F, Wang J, Zhao CM, Liu XY, Zhang XL, Li RG, Xu YJ, Hou XM, et al: A novel NKX2.5 loss-of-function mutation associated with congenital bicuspid aortic valve. Am J Cardiol 114: 1891-1895, 2014.

20. Wei D, Gong XH, Qiu G, Wang J and Yang YQ: Novel PITX2c loss-of-function mutations associated with complex congenital heart disease. Int J Mol Med 33: 1201-1208, 2014.

21. Homsy J, Zaidi S, Shen Y, Ware JS, Samocha KE, Karczewski KJ, DePalma SR, McKean D, Wakimoto H, Gorham J, et al: De novo mutations in congenital heart disease with neurodevelopmental and other congenital anomalies. Science 350: 1262-1266, 2015.

22. Li Y, Klena NT, Gabriel GC, Liu X, Kim AJ, Lemke K, Chen Y, Chatterjee B, Devine W, Damerla RR, et al: Global genetic analysis in mice unveils central role for cilia in congenital heart disease. Nature 521: 520-524, 2015.

23. Guimier A, Gabriel GC, Bajolle F, Tsang M, Liu H, Noll A, Schwartz M, El Malti R, Smith LD, Klena NT, et al: MMP21 is mutated in human heterotaxy and is required for normal left-right asymmetry in vertebrates. Nat Genet 47: 1260-1263, 2015.

24. Pan Y, Geng R, Zhou N, Zheng GF, Zhao H, Wang J, Zhao CM, Qiu XB, Yang YQ and Liu XY: TBX20 loss-of-function mutation contributes to double outlet right ventricle. Int J Mol Med 35: 1058-1066, 2015

25. Li X, Wang G, An Y, Li H, Li Y and Wu C: Association between sequence variations in RCAN1 promoter and the risk of sporadic congenital heart disease in a Chinese population. Pediatr Cardiol 36: 1393-1399, 2015.

26. Yang J, Zhu M, Wang Y, Hou X, Wu H, Wang D, Shen H, Hu Z and Zou J: Whole-exome sequencing identify a new mutation of MYH7 in a Chinese family with left ventricular noncompaction. Gene 58: 138-142, 2015.

27. Zheng J, Li F, Liu J, Xu Z, Zhang H, Fu Q, Wang J and Sun K: Investigation of somatic NKX2-5 mutations in Chinese children with congenital heart disease. Int J Med Sci 12: 538-543, 2015.

28. Wang J, Mao JH, Ding KK, Xu WJ, Liu XY, Qiu XB, Li RG, Qu XK, Xu YJ, Huang RT, et al: A novel NKX2.6 mutation associated with congenital ventricular septal defect. Pediatr Cardiol 36: 646-656, 2015.

29. Pan Y, Wang ZG, Liu XY, Zhao H, Zhou N, Zheng GF, Qiu XB, Li RG, Yuan F, Shi HY, et al: A novel TBX1 loss-of-function mutation associated with congenital heart disease. Pediatr Cardiol 36: 1400-1410, 2015.

30. Sun YM, Wang J, Qiu XB, Yuan F, Xu YJ, Li RG, Qu XK, Huang RT, Xue S and Yang YQ: PITX2 loss-of-function mutation contributes to tetralogy of Fallot. Gene 577: 258-264, 2016.

31. Lu CX, Gong HR, Liu XY, Wang J, Zhao CM, Huang RT, Xue S and Yang YQ: A novel HAND2 loss-of-function mutation responsible for tetralogy of Fallot. Int J Mol Med 37: 445-451, 2016.

32. Cao Y, Wang J, Wei C, Hou Z, Li Y, Zou H, Meng M, Wang W and Jiang L: Genetic variations of NKX2-5 in sporadic atrial septal defect and ventricular septal defect in Chinese Yunnan population. Gene 575: 29-33, 2016 
33. Chen J, Qi B, Zhao J, Liu W, Duan R and Zhang M: A novel mutation of GATA4 (K300T) associated with familial atrial septal defect. Gene 575: 473-477, 2016.

34. Yoshida A, Morisaki H, Nakaji M, Kitano M, Kim KS, Sagawa K, Ishikawa S, Satokata I, Mitani Y, Kato H, et al: Genetic mutation analysis in Japanese patients with non-syndromic congenital heart disease. J Hum Genet 61: 157-162, 2016.

35. Sun YM, Wang J, Qiu XB, Yuan F, Li RG, Xu YJ, Qu XK, Shi HY, Hou XM, Huang RT, et al: A HAND2 loss-of-function mutation causes familial ventricular septal defect and pulmonary stenosis. G3 (Bethesda) 6: 987-992, 2016.

36. McCulley DJ and Black BL: Transcription factor pathways and congenital heart disease. Curr Top Dev Biol 100: 253-277, 2012.

37. Saga Y, Kitajima S and Miyagawa-Tomita S: Mesp1 expression is the earliest sign of cardiovascular development. Trends Cardiovasc Med 10: 345-352, 2000.

38. Bondue A and Blanpain C: Mespl: A key regulator of cardiovascular lineage commitment. Circ Res 107: 1414-1427, 2010.

39. Saga Y: Genetic rescue of segmentation defect in MesP2-deficient mice by MesP1 gene replacement. Mech Dev 75: 53-66, 1998.

40. Saga Y, Miyagawa-Tomita S, Takagi A, Kitajima S, Miyazaki JI and Inoue T: MesP1 is expressed in the heart precursor cells and required for the formation of a single heart tube. Development 126: 3437-3447, 1999

41. Werner P, Latney B, Deardorff MA and Goldmuntz E: MESP1 mutations in patients with congenital heart defects. Hum Mutat 37: 308-314, 2016.

42. Schott JJ, Benson DW, Basson CT, Pease W, Silberbach GM Moak JP, Maron BJ, Seidman CE and Seidman JG: Congenital heart disease caused by mutations in the transcription factor NKX2-5. Science 281: 108-111, 1998.

43. Garg V, Kathiriya IS, Barnes R, Schluterman MK, King IN, Butler CA, Rothrock CR, Eapen RS, Hirayama-Yamada K, Joo K, et al: GATA4 mutations cause human congenital heart defects and reveal an interaction with TBX5. Nature 424: 443-447, 2003

44. Kirk EP, Sunde M, Costa MW, Rankin SA, Wolstein O Castro ML, Butler TL, Hyun C, Guo G, Otway R, et al: Mutations in cardiac T-box factor gene TBX20 are associated with diverse cardiac pathologies, including defects of septation and valvulogenesis and cardiomyopathy. Am J Hum Genet 81: 280-291, 2007

45. Lahm H, Deutsch MA, Dreßen M, Doppler S, Werner A, Hörer J, Cleuziou J, Schreiber C, Böhm J, Laugwitz KL, et al: Mutational analysis of the human MESP1 gene in patients with congenital heart disease reveals a highly variable sequence in exon 1. Eur J Med Genet 56: 591-598, 2013.
46. Wang XH, Huang CX, Wang Q, Li RG, Xu YJ, Liu X, Fang WY and Yang YQ: A novel GATA5 loss-of-function mutation underlies lone atrial fibrillation. Int J Mol Med 31: 43-50, 2013.

47. David R, Brenner C, Stieber J, Schwarz F, Brunner S, Vollmer M, Mentele E, Müller-Höcker J, Kitajima S, Lickert H, et al: MesP1 drives vertebrate cardiovascular differentiation through Dkk-1-mediated blockade of Wnt-signalling. Nat Cell Biol 10: $338-345,2008$

48. Shi X, Zirbes KM, Rasmussen TL, Ferdous A, Garry MG, Koyano-Nakagawa N and Garry DJ: The transcription factor Mesp1 interacts with cAMP-responsive element binding protein 1 (Creb1) and coactivates Ets variant 2 (Etv2) gene expression. J Biol Chem 290: 9614-9625, 2015.

49. Lyons I, Parsons LM, Hartley L, Li R, Andrews JE, Robb L and Harvey RP: Myogenic and morphogenetic defects in the heart tubes of murine embryos lacking the homeo box gene Nkx2-5. Genes Dev 9: 1654-1666, 1995.

50. Terada R, Warren S, Lu JT, Chien KR, Wessels A and Kasahara $\mathrm{H}$ : Ablation of Nkx2-5 at mid-embryonic stage results in premature lethality and cardiac malformation. Cardiovasc Res 91: 289-299, 2011.

51. Furtado MB, Wilmanns JC, Chandran A, Tonta M, Biben C, Eichenlaub M, Coleman HA, Berger S, Bouveret R, Singh R, et al: A novel conditional mouse model for Nkx2-5 reveals transcriptional regulation of cardiac ion channels. Differentiation 91: 29-41, 2016.

52. Molkentin JD, Lin Q, Duncan SA and Olson EN: Requirement of the transcription factor GATA4 for heart tube formation and ventral morphogenesis. Genes Dev 11: 1061-1072, 1997.

53. Kuo CT, Morrisey EE, Anandappa R, Sigrist K, Lu MM, Parmacek MS, Soudais C and Leiden JM: GATA4 transcription factor is required for ventral morphogenesis and heart tube formation. Genes Dev 11: 1048-1060, 1997.

54. Singh MK, Christoffels VM, Dias JM, Trowe MO, Petry M, Schuster-Gossler K, Bürger A, Ericson J and Kispert A: Tbx20 is essential for cardiac chamber differentiation and repression of Tbx2. Development 132: 2697-2707, 2005.

55. Srivastava D, Thomas T, Lin Q, Kirby ML, Brown D and Olson EN: Regulation of cardiac mesodermal and neural crest development by the bHLH transcription factor, dHAND. Nat Genet 16: 154-160, 1997.

56. Yamagishi H, Olson EN and Srivastava D: The basic helix-loop-helix transcription factor, dHAND, is required for vascular development. J Clin Invest 105: 261-270, 2000. 